\title{
EVALUASI PELAKSANAAN POSBINDU PENYAKIT TIDAK MENULAR (POSBINDU PTM) DI LINGKUNGAN TEMPAT TINGGAL
}

\section{Evaluation of Implementation of 'Posbindu PTM' in a Resident Environment}

\author{
Ekowati Rahajeng ${ }^{1}$, Enung Nurhotimah ${ }^{2}$ \\ ${ }^{1}$ Puslitbang Upaya Kesehatan Masyarakat, Badan Litbangkes \\ ${ }^{2}$ Poltekes Bandung \\ Email: ekowatir@gmail.com
}

Diterima: 12 Agustus 2020; Direvisi: 16 September 2020; Disetujui: 23 September 2020

\begin{abstract}
Posbindu PTM is one of NCD risk factor prevention and control programs in Indonesia. About 50.6\% of villages already carry out Posbindu PTM, but the prevalence of PTM risk factors remains high. This article aims to inform the results of the evaluation of Posbindu PTM implementation in residential environment, including benefits, utilization, constraints and implementation opportunities. Evaluation is carried out through a systemic review of articles related Posbindu PTM implementations published online in 20152020. Articles searched through google scholar search engine, Garuda portal, and Pubmed/PMC with keywords: Posbindu PTM implementation, utilization of Posbindu PTM, constraints and opportunities. As a selection criterion is the article is the result of research or evaluation of the implementation of Posbindu PTM and its utilization, and the article can be accessed in full text. Publications totaled 44 articles, and 19 articles met the criteria. Posbindu PTM activities generally have not been implemented regularly and comprehensively. The problem with the implementation of Posbindu PTM is that the officer is not precise in setting targets, lack of operational funds, and limited ability of cadres. Improving the benefits of Posbindu PTM requires the coaching of health workers, strengthening cadre competencies in counseling/education, and strengthening regulation in the region.
\end{abstract}

Keywords: Posbindu PTM, implementation, benefits, obstacles, opportunity

\begin{abstract}
ABSTRAK
Posbindu PTM merupakan salah satu program pencegahan dan pengendalian faktor risiko PTM di Indonesia. Sekitar 50,6\% desa sudah melaksanakan Posbindu PTM, namun prevalensi faktor risiko PTM tetap tinggi. Artikel ini bertujuan menginformasikan hasil evaluasi pelaksanaan Posbindu PTM di lingkungan tempat tinggal, meliputi manfaat, pemanfaatan, kendala dan peluang pelaksanaanya. Evaluasi dilakukan melalui sistematik reviu artikel terkait pelaksanaan Posbindu PTM yang dipublikasi secara online pada tahun 2015-2020. Artikel ditelusuri melalui mesin pencari google scholar, portal garuda, dan Pubmed/PMC dengan kata kunci: pelaksanaan Posbindu PTM, pemanfaatan Posbindu PTM, kendala dan peluang Posbindu PTM. Sebagai kriteria seleksi adalah artikel merupakan hasil penelitian atau evaluasi pelaksanaan Posbindu PTM dan pemanfaatannya, dapat menggunakan bahasa Indonesia maupun bahasa Inggris, dan artikel tersebut dapat diakses secara full text. Jumlah publikasi terkait berjumlah 44 artikel, dan 19 artikel memenuhi kriteria seleksi. Kegiatan Posbindu PTM umumnya belum dilaksanakan secara rutin dan komprehensif. Kegiatan dimanfaatkan oleh usia 35 tahun ke atas dan pasien PTM. Permasalahan pelaksanaan Posbindu PTM adalah Petugas kurang tepat dalam menetapkan sasaran, kurangnya dana operasional, dan keterbatasan kemampuan Kader melakukan konseling. Dukungan pemangku kepentingan merupakan peluang berkembangnya Posbindu PTM. Peningkatan manfaat Posbindu PTM memerlukan pembinaan petugas kesehatan, penguatan kompetensi kader dalam melakukan konseling/edukasi, dan penguatan regulasi di daerah.
\end{abstract}

Kata kunci: Posbindu PTM; pelaksanaan; manfaat; kendala; peluang 


\section{PENDAHULUAN}

Prevalensi Penyakit Tidak Menular (PTM) dan faktor risikonya di Indonesia, terus mengalami peningkatan (Kemenkes RI, 2018). Salah satu program yang diharapkan dapat mencegah dan mengendalikan faktor risiko PTM di Indonesia adalah Posbindu (Pos Pembinaan Terpadu) PTM. Program tersebut dikembangkan merujuk pada hasil studi operasional pengendalian faktor risiko bersama PTM Utama di Kota Depok Jawa Barat (Rahajeng et al., 2004). Pelaksanaan kegiatan Posbindu PTM secara rutin, periodik dan berkelanjutan serta layanan PTM secara komprehensif di Puskesmas, efektif menurunkan prevalensi faktor risiko PTM (Rahajeng et al., 2006; Rahajeng, Oemiyati and Kusumawardani, 2006). Melalui kegiatan Posbindu PTM, pegetahuan masyarakat tentang PTM dan faktor risikonya meningkat, faktor risiko PTM dapat terdeteksi secara dini, selanjutnya dapat dicegah dan dikendalikan melalui konseling di Posbindu PTM dan pengobatan yang tepat melalui layanan di Puskesmas. Sejak tahun 2011 Posbindu PTM telah menjadi program nasional, diperkuat dengan Peraturan Menteri Kesehatan (Permenkes) nomor 71 tahun 2015.

Kegiatan pencegahan dilakukan melalui promosi membudayakan perilaku 'CERDIK', sementara pengendalian dilaksanakan dengan deteksi dini dan tata laksana dini melalui kegiatan Posbindu PTM dan layanan Pandu PTM di Puskesmas (Kementerian Kesehatan R, 2015). Kementerian Kesehatan telah menyusun pedoman umum dan petunjuk teknis Posbindu PTM sebagai acuan pelaksanaan kegiatan. Pelatihan program bagi penanggung jawab program dan petugas kesehatan di seluruh provinsi dan kabupaten/kota serta pelatihan kader, telah dilaksanakan secara berjenjang. Distribusi dana dekonsentrasi dan Kit Posbindu PTM telah dilakukan ke seluruh provinsi untuk merintis dan memotivasi pelaksanaan program. Kegiatan Posbindu PTM di desa diharapkan dapat tumbuh dan berkembang seluruh kabupaten/kota, melalui pemanfaatan Dana Alokasi Khusus (DAK), Biaya Operasional Kesehatan, serta dukungan Pemerintah Daerah dan para pemangku kepentingan melalui kemitraan. Prevalensi faktor risiko PTM diharapkan dapat dicegah dan dikendalikan, melalui kegiatan Posbindu PTM. (Kementerian Kesehatan RI, 2015; Direktorat Jenderal Pencegahan dan Pengendalian Penyakit, 2017) .

Pada tahun 2019, sekitar 40.999 desa atau 50,6\% dari 80.983 desa/kelurahan di Indonesia sudah melakukan kegiatan Posbindu PTM (Kementerian Kesehatan RI, 2019). Namun kegiatan tersebut belum memberikan dampak terhadap penurunan prevalensi faktor risiko PTM. Evaluasi pelaksanaan program Posbindu PTM secara nasional sementara ini belum dilakukan. Artikel ini bertujuan memberikan informasi hasil evaluasi pelaksanaan Posbindu PTM di lingkungan tempat tinggal, meliputi manfaat, pemanfaatan, kendala dan peluang pelaksanaanya. Evaluasi dilakukan melalui sistematik reviu artikel terkait pelaksanaan Posbindu PTM yang dipublikasi secara online pada tahun 2015-2020.

\section{BAHAN DAN CARA}

Artikel ini disusun berdasarkan hasil reviu sistematik terhadap artikel-artikel terkait pelaksanaan Posbindu PTM yang telah dipublikasikan melalui jaringan internet. Penelusuran dilakukan menggunakan mesin pencari google scholar (Google search), portal garuda, dan Pubmed/PMC dengan kata kunci: pelaksanaan Posbindu PTM, pemanfaatan Posbindu PTM, kendala dan peluang Posbindu PTM. Artikel dibatasi pelaksanaan kegiatan Posbindu PTM di lingkungan tempat tinggal di Indonesia, dari publikasi pada tahun 2015 sampai dengan tahun 2020. Prosedur reviu sistematik dilakukan dengan kriteria yaitu, artikel merupakan hasil penelitian atau evaluasi pelaksanaan Posbindu PTM dan pemanfaatannya, dapat menggunakan bahasa Indonesia maupun bahasa Inggris, dan artikel tersebut dapat diakses secara full text.

Jumlah artikel yang diperoleh hingga tanggal 25 Juli tahun 2020 seluruhnya berjumlah 44 artikel, yaitu 42 artikel dalam bahasa Indonesia dan 2 artikel dalam bahasa Inggris, artikel sesuai topik yaitu terkait pelaksanaan Posbindu PTM 26 artikel. 
Sebagian artikel yang didapat membahas hubungan dan pengaruh faktor risiko terhadap PTM, serta pelaksanaan surveilans dengan sumberdata kegiatan Posbindu PTM. Sementara artikel yang sesuai dengan kriteria berjumlah 19 artikel (Tabel 1).

Tabe1. Hasil Penelusuran Artikel

\begin{tabular}{ll}
\hline Mesin pencari & \\
\hline Hasil penelusuran sesuai kata kunci, & \\
Fulltext, tahun 2015-2020 & 44 artikel \\
Sesuai topik & 26 artikel \\
Eligible sesuai kriteria & 19 artikel \\
\hline Hasil seleksi & 19 artikel terpilih \\
\hline
\end{tabular}

Selanjutnya seluruh artikel yang memenuhi kriteria dibaca, diperiksa, dan dilakukan ekstraksi informasi dan deduksi konten sesuai tujuan evaluasi. Informasi yang terkumpul kemudian dikelompokkan menurut manfaat, pemanfaatan, kendala, dan peluang dalam meningkatkan kegiatan
Posbindu PTM. Informasi kualitatif yang sesuai tujuan diolah dengan Atlas.ti, untuk melengkapi informasi yang ditelusuri. Selanjutnya dilakukan sintesis untuk mendapatkan informasi lebih mendalam terkait pelaksanaan dan pemanfaatan Posbindu PTM.

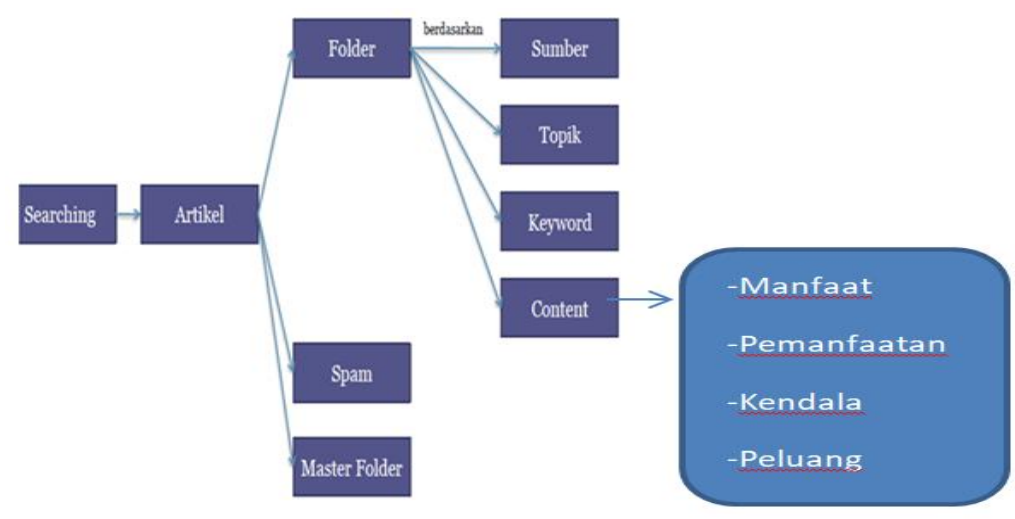

Gambar 1. Proses seleksi, ektraksi dan review artikel

Gambar 1 diatas merupakan gambaran proses seleksi dan ekstraksi artikel secara sistematik sesuai dengan tujuan evaluasi. Yaitu dengan melakukan seleksi artikel-artikel dan ekstraksi informasi sesuai tujuan penulisan. Selanjutnya artikel yang memenuhi kriteria tersebut dilakukan ekstraksi informasi meliputi manfaat, pemanfatannya, kendala dan peluang dalam pelaksanaan Posbindu PTM, dengan ruang lingkup sebagai berikut :

1. Manfaat Posbindu PTM merupakan faedah utama dilaksanakannya kegiatan Posbindu PTM, sesuai Petunjuk Teknis. Misalnya, bermanfaat untuk deteksi dan tindak lanjut dini, meningkatkan 136 mencegah dan mengendalikan faktor risiko PTM, dan menurunkan prevalensi faktor risiko PTM,

2. Pemanfaatan Posbindu PTM meliputi karakteristik peserta dan cakupan penduduk yang memanfaatkan kegiatan Posbindu PTM, pemanfaatan data dan informasi kegiatan Posbindu PTM, dan manfaat lainnya bagi masyarakat.

3. Kendala merupakan hambatan teknis operasional yang dihadapi dalam menyelenggarakan kegiatan Posbindu PTM sesuai Petunjuk Teknis Kementerian Kesehatan, misalnya keterbatasan sumberdaya manusia 
(SDM), sarana prasarana, biaya, dukungan dan partisipasi masyarakat

4. Peluang merupakan faktor-faktor yang memungkinkan terlaksananya kegiatan Posbindu PTM, antara lain dukungan pemangku kepentingan terkait (Pemerintah daerah, Kepala Desa, sektor lain termasuk swasta, lembaga masyarakat dan lainnya), termasuk peningkatan kuantitas dan kualitas penyelenggaraan, serta perluasan cakupan penduduk.

\section{HASIL}

Pada Tabel 2, dapat dilihat judul dan penulis artikel, metode dan jurnal/sumber publikasi serta kesimpulan hasil penelitian dari 19 artikel yang memenuhi kriteria seleksi, yaitu yang merupakan hasil penelitian terkait evaluasi pelaksanaan dan pemanfaatan Posbindu PTM di lingkungan tempat tinggal, dan dipublikasi secara online pada tahun 2015-2020.

Tabel 2. Penulis, judul, metode dan jurnal/sumber artikel terkait pelaksanaan Posbindu PTM Tahun 2015-2020

\begin{tabular}{llll}
\hline $\begin{array}{l}\text { Judul } \\
\text { (penulis, tahun publikasi) }\end{array}$ & $\begin{array}{l}\text { Metode } \\
(\text { Jurnal/Sumber Artikel) })\end{array}$ & Kesimpulan Hasil \\
\hline 1. & $\begin{array}{l}\text { Dukungan keluarga dan Tokoh } \\
\text { masyarakat terhadap keaktifan } \\
\text { penduduk ke Posbindu PTM }\end{array}$ & $\begin{array}{l}\text { Studi Kroseksional } \\
\text { (Jurnal Kesehatan }\end{array}$ & $\begin{array}{l}\text { Dukungan keluarga dan tokoh masyarakat } \\
\text { meningkatkan keaktifan penduduk ke Posbindu }\end{array}$ \\
$\begin{array}{ll}\text { Masyarakat, 11(1) }) & \text { PTM and Cahati, 2015) }\end{array}$ &
\end{tabular}

2. Gambaran Proses Kegiatan Pos Pembinaan Terpadu Penyakit Tidak Menular di Puskesmas Sempu Kabupaten Banyuwangi (Dwi Astuti dkk, 2016)

3. The Empowerment of Integrated Development Post of Non-Communicable Diseases in Efforts to Prevent NonCommunicable Diseases (Yandrizal dkk, 2016)

4. Faktor Pemanfaatan Program Posbindu PTM (Wiwi dkk, 2018)

5. Faktor-Faktor yang Berhubungan dengan Pemanfaatan Posbindu PTM Di Wilayah Kerja Puskesmas Kecamatan Setiabudi Kota Jakarta Selatan (Sari dkk, 2018)

6. Efektivitas Program Pos Pembinaan Terpadu (Posbindu) Penyakit Tidak Menular (PTM) di Desa Anggaswangi Kecamatan Sukodono Sidoarjo (Jayusman dkk, 2018)

7. Evaluasi kualitatif program penyakit tidak menular berbasis Posbindu di wilayah kerja Puskesmas Muara Bungo I (Grace Sicilia dkk, 2018)
Studi Kroseksional, kuantitatif dan kualitatif. (Jurnal Pustaka Kesehatan, 4(1))

Studi eksplorasi, kualitatif dan kuantitatif. (International Journal of Public Health Science (IJPHS), 5(3))

Explanatory Research dengan rancangan cross sectional

(Jurnal Kesehatan Ilmiah Indoneisa, 3(2)).

Studi Kroseksional, kuantitatif.

(Jurnal Kebijakan Kesehatan Indonesia: JKKI, 07(02))

Studi deskriptif dengan pendekatan kualitatif. (Jurnal Ilmu Administrasi Negara, 7(2))

Studi Evaluasi dengan pendekatan kualitatif (Jurnal Kebijakan Kesehatan Indonesia : JKKI, 7(2) )
Kegiatan Posbindu PTM berbeda dengan juknis dan pedoman. Hal tersebut dipengaruhi SDM, pelatihan belum maksimal, kurangnya sarana dan peralatan, kurangnya kesadaran masyarakat, pembiayaan yang belum mandiri dan cara penyelenggaraan tidak rutin setiap bulannya Peserta Posbindu PTM merasakan manfaat kegiatan, dan ada hubungan antara perilaku datang ke Posbindu PTM dengan perilaku mencegah PTM. Stakeholder dan masyarakat mau berperan pada Posbindu PTM setelah memahami tujuan dan manfaat Posbindu PTM Pendidikan, pekerjaan, pengetahuan, sikap, persepsi petugas kesehatan dan kader berpengaruh terhadap pemanfaatan Posbindu PTM.

Pemanfaatan Posbindu PTM masih rendah yakni 57,9\%, karena pengetahuan masyarakat masih rendah dan jumlah kader tidak cukup. Dukungan kader merupakan faktor dominan terhadap pemanfaatan Posbindu PTM. Kader terlatih lebih memilih menjadi kader jumantik karena mendapat uang transport Layanan kepada anggota aktif secara kualitas sudah efektif untuk menjaga kesehatan dari risiko PTM. Namun untuk mencapai jumlah sasaran program (penduduk 15-59 tahun) secara kuantitas belum efektif. Komunikasi dan sosialisasi kepada organisasi yang ada di desa (pengajian, karang taruna dll) belum dilakukan Pelaksanaan Posbindu PTM belum optimal. Diperlukan dukungan lintas sektor yang diprakarsai langsung oleh Bupati 
8. Optimalisasi Peran Kader Posbindu Dalam P4Gn dan PTM

(Ana M dkk, 2018)

9. Iptek bagi masyarakat (IbM) desa terong dan Jatimulyo dalam pengelolaan hipertensi dan Diabetes Melitus (Pradana dkk, 2018)

10. Faktor-Faktor yang Mempengaruhi Pemanfaatan Pos Pembinaan Terpadu Penyakit Tidak Menular (Posbindu PTM) di Wilayah Kerja Puskesmas Glugur Darat Tahun 2018

(Maharani dkk, 2018)

11. Strategi Penguatan Program Posbindu Penyakit Tidak Menular Di Kota Bogor (Nugraheni dkk, 2018)

12. Evaluasi pelaksanaan Program Posbindu PTM Puskesmas Sukolilo I Kab. Pati (Suhbah dkk, 2019)

13. Peran Masyarakat dalam Kegiatan Posbindu PTM Di Kelurahan Lumpur Kabupaten Gresik

(Mashdariyah dkk, 2019)

14. Sekolah Kader : Sebagai Upaya Peningkatan Pengetahuan dan Keterampilan Kader Remaja Posbindu PTM Di Dusun Jaten, Yogyakarta

(Najiyati dkk, 2019)

15. Community Knowledge Level About The Utilization Of Inte grated Coaching Pos Of Non communicbale Disease (Posbin du PTM) With The Prevalence Of Noncommunicable Disease Age 15 - 59 In Working Area Of Wonosobo Health Center In Srono Banyuwangi 2018 (Sasongko dkk, 2019)

16. Analisis Pelaksanaan Program Pos Pembinaan Terpadu Penyakit Tidak Menular di Kota Solok (Primiyani, 2019)

17. An Analysis on the
Studi Intervensi

(Jurnal Pengabdian

kepada Masyarakat;2(2))

Studi Operasional

(Asian Journal of

Innovation and

Entrepreneurship

Volume. 03, Issue. 02)

Studi Krosseksional

(Jurnal Kesehatan

Masyarakat dan

Lingkungan Hidup, (2))

Studi Kasus

(Jurnal Ilmu Kesehatan Masyarakat, 9(3) )

Studi Evaluasi dengan pendekatan kualitatif (Jurnal Kesehatan Masyarakat (e-Journal) Volume 7, Nomor 4)

Studi Kroseksional (Jurnal Midwiferia, Universitas Muhamadiyah Sidoarjo, 5(2) )

Studi Operasional (pretest post-test dan mixed method)

(Journal of Community Empowerment for Health, 2(1) )

Studi Kroseksional (Proceeding The 4th International Nursing Conference "Life Cycle Approach For Successful Aging Institution of research and community service Jember)

Analisis Kebijakan dengan pendekatan kualitatif (Jurnal Kesehatan Andalas; 8(2))

Studi Kebijakan dengan
Kader Posbindu Antinarsis dapat membantu melakukan pengendalian penyakit hipertensi dan Diabetes Mellitus melalui monitoring faktor resiko pada pelayanan Posbindu.

Pelaksanaan Posbindu PTM mampu mendeteksi, memantau dan meningkatkan penatalaksanaan pasien DM dan hipertensi di kedua desa dalam rangka mencapai kondisi klinis terkontrol Pemanfaatan Posbindu PTM masih rendah $(37,8 \%)$. Terdapat pengaruh antara pekerjaan, pengetahuan, dukungan kader, dan dukungan keluarga dengan pemanfaatan Posbindu PTM Masyarakat berpengetahuan kurang berisiko tidak memanfaatkan Posbindu PTM

Alternatif strategi penguatan Posbindu PTM dapat dilakukan melalui kegiatan pengobatan gratis, kegiatan sepeda santai, dan doorprize bagi peserta untuk menarik minat warga, dan kerjasama lintas sektor agar kegiatan Posbindu PTM semakin komprehensif.

Pelaksanaan program Posbindu PTM kurang optimal. Sebagian besar petugas dan kader belum terlatih dan belum ada SK penugasan. Dana, sarana dan prasarana terbatas. Perencana an, koordinasi, pembinaan dan pengawasan, serta target program, belum ada.

Umur, tingkat pengetahuan dan dukungan kader meningkatkan peranserta masyarakat dalam kegiatan Posbindu PTM

Pengetahuan dan keterampilan kader remaja dalam pelaksanaan posbindu PTM dapat ditingkatkan melalui pelatihan. Keterlibatan remaja secara aktif efektif dalam meningkatkan partisipasi remaja mengikuti kegiatan Posbindu PTM, namun perlu pendampingan,

Pengetahuan pemanfaatan Posbindu PTM yang cukup dapat menurunkan prevalensi faktor risiko PTM.

Pelaksanaan Posbindu PTM belum optimal dan kunjungan masih rendah. Ada SK Walikota namun belum tersosialisasikan. Pendanaan dari APBD dan BOK. Perencanaan, monitoring dan evaluasi belum baik. Sarana dan prasarana dan SDM belum memadai. Pelaksanaan sesuai petunjuk teknis, namun kader belum menguasai. Kemitraan lintas sektor belum terjalin. Sosialisasi dan advokasi belum dilakukan. Pelaksana program belum sepenuhnya 
Implementation of the Integrated Guidance Post (Posbindu) Activities for NonCommunicable Diseases At Bogor City in 2018'

(Alfiyah dkk, 2019)

18. Pemanfaatan Pos Pembinaan Terpadu (Posbindu) Penyakit Tidak Menular (PTM) Pada Penderita Hipertensi (Haiti dkk, 2020)

19. Implementasi Program Pos Pembinaan Terpadu Penyakit Tidak Menular di Provinsi Jawa Barat Tahun 2015 (Andayasari dkk, 2020) pendekatan kualitatif (Journal of Indonesian Health Policy and Administration, 4(1)

Studi Kroseksional (Jurnal Ners dan Kebidanan, Volume 5)

Studi operasional, dengan pendekatan kuantitatif dan kualitatif (Jurnal Penelitian dan Pengembangan Pelayanan Kesehatan; 3 (3)) memahami sasaran dan pelaksanaan belum sesuai petunjuk teknis. Kemampuan kader kurang memadai dan memerlukan pelatihan atau rekrutmen kader baru. Dukungan dari pemangku kepentingan membutuhkan regulasi khusus

Peningkatan derajat kesehatan dapat diupayakan melalui peningkatan pemanfaatan pelayanan Posbindu PTM

Pendukung pelaksanaan program pedoman Posbindu PTM, Posbindu Kit, kemampuan kader mengidentifikasi faktor risiko PTM, kesiapan tenaga medis dan paramedik dalam penanganan PTM. Penghambatnya adalah keterbatasan dana, kader kurang mampu melakukan penyuluhan, dan kurangnya dukungan perangkat desa
Hasil penelusuran mendapatkan 8 artikel disusun berdasarkan hasil studi krosseksional, 3 artikel merupakan hasil studi operasional dan 3 artikel hasil studi evaluasi, artikel lainnya merupakan hasil studi kasus, studi intervensi, studi eksplorasi, dan analisis kebijakan (Tabel 2). Kegiatan Posbindu PTM pada 18 artikel yang terseleksi di atas sebagian besar berada di wilayah Indonesia bagian barat, yaitu di Provinsi Jawa Timur yaitu di wilayah Kabupaten Tulungagung, Kota Malang, Kabupaten Banyuwangi, dan Kota Gresik. Di
Jawa Tengah yaitu di Kota Semarang, dan Kabupaten Pati. Propinsi DI Jogyakarta yaitu di Kota Jogyakarta, Kabupaten Bantul dan Kabupaten Sleman. Propinsi Sumatera Barat di Kota Solok. Provinsi Bengkulu di Kota Bengkulu. Provinsi Jambi di Kota Muara Bungo. Provinsi DKI Jakarta, di Kecamatan Setiabudi Jakarta Selatan. Provinsi Sumatera Utara di Kota Medan dan Kabupaten Tapanuli Selatan. Propinsi Jawa Barat Kabupaten Tasikmalayadan Kota Bogor.

Tabel 3. Hasil Ekstraksi Artikel

\begin{tabular}{|c|c|c|c|}
\hline No & Konten & & Rujukan Artikel *) \\
\hline & Manfaat & & \\
\hline 20. & $\begin{array}{l}\text { Meningkatkan pengetahuan tentang PTM dan } \\
\text { faktor risikonya }\end{array}$ & : & $1,2,3,4,5,6,7,8,9,10,11,12,13,14,15,16,17,18,19$ \\
\hline 21. & Deteksi dan pemantauan faktor risiko PTM & : & $1,2,3,4,5,6,7,8,9,10,11,12,13,14,15,16,17,18,19$ \\
\hline 22. & Tindak lanjut dini faktor risiko PTM & : & $3,5,6,9,11,16$ \\
\hline 23. & $\begin{array}{l}\text { Mencegah dan mengendalikan faktor risiko } \\
\text { PTM } \\
\text { Pemanfaatan }\end{array}$ & : & $6,9,15,18$ \\
\hline 1. & Rutin setiap bulan & & $3,5,6,8,11,15,18$ \\
\hline 2. & Peserta 15 tahun ke atas & & 8,14 \\
\hline 3. & Peserta 35 tahun ke atas & : & $1,2,3,4,5,6,7,9,10,11,12,13,15,16,17,18,19$ \\
\hline 4. & Cakupan penduduk $<25 \%$ & & $1,2,3,5,6,7,9,10,11,12,13,14,15,16,17,18,19$ \\
\hline 5. & Cakupan penduduk $>=25 \%$ & & 8,11 \\
\hline 6. & $\begin{array}{l}\text { Pemanfaatan data faktor risiko PTM } \\
\text { Kendala }\end{array}$ & & $1,2,3,4,5,6,7,8,9,10,11,12,13,14,15,16,17,18,19$ \\
\hline 1. & Keterbatasan petugas kesehatan & & $4,7,11,12$ \\
\hline 2. & Keterbatasan jumlah kader & & $4,5,11,12$ \\
\hline 3. & Keterbatasan kemampuan kader & : & $1,2,3,4,5,6,7,8,9,10,11,12,13,14,15,16,17,18,19$ \\
\hline 4. & Keterbatasan sarana dan dana & & $2,7,12,16,18,19$ \\
\hline 5. & Kurang/tidak ada dukungan & & $1,2,5,6,7,10,11,12,16,18,19$ \\
\hline
\end{tabular}




\begin{tabular}{lll} 
& Peluang & \\
1. & Dukungan pemangku kepentingan & $2,3,5,8,9,16$ \\
2. & Dukungan legalitas & 9,16 \\
3. & Dukungan biaya dan sarana & 3,16 \\
4. & Dukungan kemitraan & 5,14 \\
\hline
\end{tabular}

*) Nomor urut artikel pada tabel 2

\section{Manfaat Posbindu PTM}

Sebagian besar artikel melaporkan pelaksanaan dan pemanfaatan Posbindu PTM belum optimal dan belum sesuai dengan pedoman Posbindu PTM. Sementara pelaksanaan Posbindu PTM secara optimal dan komprehensif dapat mengontrol (mengendalikan) faktor risiko PTM dan berhubungan dengan rendahnya prevalensi faktor risiko PTM, namun cakupan penduduk yang dijangkau kegiatan Posbindu PTM masih rendah (Dwi Astuti, Prasetyowati and Ariyanto, 2016; Jayusman and Widiyarta, 2018; Pradana, Marfianti and Trimulyaningsih, 2018; Sasongko, Nanda and Fitriyati, 2019; Haiti, Anggraini and Tominik, 2020).

Manfaat Posbindu PTM dapat diketahui lebih lengkap pada Tabel 3. Pelaksanaan kegiatan umumnya meningkatkan pengetahuan masyarakat tentang PTM dan faktor risikonya. Pelaksanaan Posbindu PTM bermanfaat untuk deteksi dini dan pemantauan faktor risiko PTM. Hanya 6 artikel $(<50 \%)$ yang melaporkan pelaksanaan Posbindu PTM bermanfaat untuk tindak lanjut dini, dan 4 artikel (kurang 25\%) melaporkan bahwa kegiatan Posbindu PTM bermanfaat untuk mencegah dan mengendalikan faktor risiko PTM. Penelusuran lebih lanjut mendapatkan bahwa Posbindu PTM dapat memantau perkembangan klinis penderita DM dan hipertensi sehingga sangat membantu puskesmas dalam memberikan pengobatan (Pradana, Marfianti and Trimulyaningsih, 2018).

\section{Pemanfaatan Posbindu PTM}

Tabel 3 juga memperlihatkan deskripsi pemanfaatan Posbindu PTM umumnya belum optimal. Posbindu PTM umumnya belum diselenggarakan rutin setiap bulan. Sasaran penduduk yang telah dijangkau umumnya kurang dari $25 \%$ dan sebagian besar berusia 35 tahun ke atas. Posbindu PTM lebih banyak dimanfaatkan kelompok usia lanjut, karena sebagian besar pelaksanaan kegiatan diintegrasikan dengan Posyandu Lansia. Pemanfaatan data kegiatan Posbindu umumnya terkait data faktor risiko PTM. Berdasarkan penelusuran lebih lanjut diketahui bahwa pengguna data sebagian besar adalah mahasiswa dan dosen dari perguruan tinggi setempat, untuk untuk pembelajaran, penelitian dan pengabdian masyarakat.

$\begin{array}{ccc}\text { Faktor } & \text { yang } & \text { mempengaruhi } \\ \text { pemanfaatan } & \text { Posbindu } & \text { PTM adalah }\end{array}$ pekerjaan, pengetahuan, dukungan kader, dan dukungan keluarga (Maharani, Sibagariang and Ginting, 2018; Sari and Savitri, 2018). Masyarakat mau berperanserta dan memanfaatkan kegiatan Posbindu PTM setelah mengetahui tujuan dan manfaatnya (Yandrizal et al., 2016). Dukungan keluarga dan tokoh masyarakat meningkatkan keaktifan penduduk ke Posbindu PTM (Umayana and Cahati, 2015). Sementara persespsi petugas kesehatan dan kader tentang Posbindu PTM juga berpengaruh terhadap pemanfaatan Posbindu PTM (Wiwi, Yanna and Panggabean, 2018). Dari penelusuran lebih mendalam diketahui bahwa Posbindu PTM tidak hanya dimanfaatkan oleh penduduk yang sehat. Penderita PTM banyak memanfaatkan kegiatan Posbindu PTM (Pradana, Marfianti and Trimulyaningsih, 2018; Suhbah, Suryawati and Kusumastuti, 2019; Haiti, Anggraini and Tominik, 2020).

Pemanfaatan Posbindu PTM masih rendah, karena komunikasi dan sosialisasi kepada organisasi yang ada di desa (pengajian, karang taruna dll) belum dilakukan (Jayusman and Widiyarta, 2018). Pelaksanaan kegiatan Posbindu PTM di Desa Terong dan Jatimulyo di wilayah Kecamatan Dlingo Bantul telah direncanakan dan dilaksanakan secara optimal sesuai pentunjuk teknis, mulai dari pelatihan kader sampai 
dengan evaluasi kegiatan. Kegiatan. Posbindu PTM terselenggara secara rutin setiap bulan. Posbindu PTM memberikan manfaat pengembangan Ilmu Pengetahuan dan Teknologi (Iptek) bagi masyarakat pedesaan (Pradana, Marfianti and Trimulyaningsih, 2018). Sementara Nugraheni menawarkan aternatif strategi yaitu penambahan kegiatan seperti pengobatan gratis, kegiatan sepeda santai, dan doorprize bagi peserta untuk menarik minat warga agar mau berpartisipasi hadir dalam Posbindu PTM (Nugraheni and Hartono, 2018) .

\section{Kendala Pelaksanaan Posbindu PTM}

Seluruh artikel melaporkan adanya keterbatasan kemampuan kader dalam pelaksanaan Posbindu PTM utamanya kemampuan melakukan edukasi dan konseling pencegahan dan pengendalian PTM. Sekitar $25 \%$ artikel menyampaikan kendala keterbatasan saranan dan biaya oprasional. Rendahnya kapasitas SDM dalam mengelola Posbindu PTM dan kemampuan pendanaan yang terbatas menjadi ancaman keberlanjutan program Posbindu PTM (Grace, 2018). Sementara sebagian besar pelaksanaan Posbindu PTM belum mendapatkan dukungan dari pemangku kepentingan setempat (Tabel 3). Hasil penelusuran mendapatkan pemangku kepentingan belum mau berperan pada Posbindu PTM karena belum memahami tujuan dan manfaat Posbindu PTM. Setelah mengetahui tujuan dan manfaat Posbindu PTM dengan jelas dukungan para pemangku kepentingan meningkat secara bermakna (Yandrizal et al., 2016).

Studi evaluasi mendapatkan program Posbindu PTM belum dikelola dengan baik. Lebih lanjut diketahui, adanya keterbatasan pengetahuan petugas kesehatan dalam mengelola program Posbindu PTM, karena petugas kesehatan belum mengikuti pelatihan. Petugas kesehatan dan kader Posbindu PTM yang belum mengikuti pelatihan cukup banyak. Sebagaimana terungkap bahwa pemahaman konsep Posbindu PTM dari pengelola program belum sesuai dengan pedoman umum pelaksanaan Posbindu PTM. Program
Posbindu PTM belum dikelola sesuai petunjuk teknis yang telah ditetapkan Kementerian Kesehatan. Plan Of Action (POA) belum ada, sosialisasi dan advokasi kepada pemangku kepentingan belum pernah dilakukan. Monitoring dan evaluasi masih belum optimal, dan output posbindu PTM belum tercapai. Sementara harapan masyarakat terhadap kegiatan Posbindu PTM sangat tinggi (Primiyani, Masrul and Hardisman, 2019).

\section{Peluang Pelaksanaan Posbindu PTM}

Pada Tabel 3 dapat dilihat peluang terselenggaranya Posbindu PTM umumnya adalah adanya dukungan pemangku kepentingan antara lain Bupati, Walikota, Camat, Lurah/Kepala Desa, tokoh masyarakat, dunia usaha, organisasi masyarakat setempat, keluarga dan masyarakat setempat. Sebanyak 7 artikel melaporkan adanya dukungan tersebut, dan sebagian besar dukungan berasal dari keluarga dan masyarakat pada umumnya. Dukungan legalitas, biaya dan sarana ditemukan di Kota Solok dalam bentuk Surat Keputusan (SK) Walikota, di Kota Bengkulu dalam bentuk SK Walikota, serta di Desa Terong dan Desa Jatimulyo Kecamatan Dlingo Bantul dalam bentuk SK Kepala Desa (Yandrizal et al., 2016; Pradana, Marfianti and Trimulyaningsih, 2018; Primiyani, Masrul and Hardisman, 2019). Kemitraan dalam pelaksanaan Posbindu PTM baru ditemukan di Jakarta Selatan Provinsi DKI Jakarta dalam bentuk Corporate Social Responsibilty (CSR), arisan warga dan sumbangan Tokoh Masyarakat (Sari and Savitri, 2018).

Penelusuran lebih lanjut mendapatkan informasi bahwa adanya SK Walikota tentang pelaksanaan Posbindu PTM di Kota Solok tidak cukup mendukung pelaksanaan kegiatan secara optimal. Dukungan biaya, sarana dan prasarana dalam pelaksanaan Posbindu PTM dapat diperoleh melalui Perwako (..) tentang SPM (..) bidang kesehatan (Primiyani, Masrul and Hardisman, 2019). Dukungan keluarga dan tokoh masyarakat diketahui telah meningkatkan keaktifan kegiatan Posbindu PTM (Umayana and Cahati, 2015). Terdapat 
potensi besar masyarakat pada kegiatan Posbindu PTM. (Grace Sicilia, Fatwa Sari Tetra Dewi, 2018). Sementara dukungan kader yang meningkatkan manfaat adalah kader yang telah siap dalam menjalankan fungsi Posbindu PTM (Ambarwati, 2019).

Inisiasi memberdayakan remaja sebagai kader Posbindu PTM ditemukan pada penelusuran pelaksanaan kegiatan di daerah Sleman DI Yogyakarta. Telah dilakukan inovasi dengan mengoptimalkan peran remaja sebagai kader Posbindu PTM melalui pembentukan Kader Antinarsis (antinarkoba, hipertensi, dan kencing manis). Kader Posbindu Antinarsis dapat membantu melakukan pengendalian penyakit hipertensi dan Diabetes Mellitus melalui monitoring faktor risiko PTM pada kegiatan Posbindu PTM (Ana Mardiyaningsih, Nur Ismiyati, 2018). Untuk melatih kader remaja diperlukan pendekatan sesuai dengan keadaan dan kondisi remaja yaitu dengan pendekatan melalui media sosial, grup whatsApp, dan menggunakan media edukasi berupa filler untuk remaja (Najiyati et al., 2019).

\section{PEMBAHASAN}

Sesuai Norma Standar Pedoman dan Kriteria (NSPK) Posbindu PTM yang ditetapkan oleh Kementerian Kesehatan, Posbindu PTM adalah bentuk peranserta masyarakat dalam kegiatan pemantauan dan deteksi dini faktor risiko PTM secara terpadu, rutin-periodik, serta tindak lanjut dini faktor risiko PTM yang ditemukan dengan konseling dan/atau edukasi pencegahan dan pengendalian faktor risiko PTM. Kegiatan ini dikembangkan sebagai bentuk kewaspadaan dini, mengingat hampir semua faktor risiko PTM tidak memberikan gejala pada kasus yang mengalaminya. Apabila faktor risiko yang ditemukan pada kasus tidak berubah selama 3 bulan berturut turut, maka kasus segera dirujuk ke fasilitas pelayanan kesehatan dasar/Puskesmas (Rahajeng et al., 2012, 2013). Hasil penelusuran mendapatkan sebagian besar pelaksanaan Posbindu PTM belum optimal dan tidak komprehensif sebagaimana NSPK yang ditetapkan. Berdasarkan hasil penelusuran ini maka dapat diduga bahwa, tidak berpengaruhnya penyelenggaraan Posbindu PTM di 50,9\% desa di Indonesia terhadap prevalensi faktor risiko PTM kemungkinan disebabkan oleh pelaksanaan program yang belum optimal.

Manfaat utama program Posbindu PTM adalah mencegah dan mengendalikan faktor risiko PTM, melalui tindak lanjut dini. Sebagian besar pelaksanaan kegiatan Posbindu PTM tidak diikuti dengan tindak lanjut dini karena keterbatasan jumlah petugas kesehatan dan keterbatasan kemampuan kader dalam melakukan edukasi dan konseling. Keterbatasan tersebut dilaporkan karena cukup banyak kader belum mendapatkan pelatihan. Sementara bagi kader yang sudah mendapatkan pelatihan, pengetahuan dan keterampilan yang dimili dinilai kurang maksimal. Faktor-faktor yang mempengaruhi pengetahuan antara lain: pendidikan, informasi, sosial budaya dan ekonomi, lingkungan, pengalaman, dan usia. Bila seseorang mendapatkan pengetahuan teoritis, dia bisa menggunakan pengetahuan ini untuk mengembangkan ketrampilannnya. Lamanya waktu dan metode pembelajaran yang diterapkan berpengaruh terhadap pengetahuan dan keterampilan yang diperoleh seseorang (Notoatmodjo, 2012).

Sementara ini, pelatihan pelaksanaan program Posbindu PTM telah dilakukan secara berjenjang di seluruh kabupaten/kota, menggunakan kurikulum dan modul yang telah disiapkan Kementerian Kesehatan pada tahun 2012. Mengingat pentingnya peran petugas dan kader Posbindu PTM dalam mencegah dan mengendalikan faktor risiko PTM, maka evaluasi dan pengembangan kurikulum, modul pelatihan dan metode pembelajaran perlu dilakukan. Kemajuan teknologi komunikasi dan informasi serta metode pembelajaran yang saat ini telah berkembang pesat, perlu dimanfaatkan guna peningkatan kapasitas petugas dan kader. Penggunaan metode pembelajaran $e$ learning dalam meningkatkan kualitas pembelajaran dengan kelas virtual (elearning) mampu meminimalkan perbedaan cara mengajar dan materi, sehingga memberikan standar kulitas pembelajaran yang lebih konsisten. Sistem e-Learning diperlukan untuk mengantisipasi kendala jarak, geografi, dan perkembangan 
pengetahuan, dengan dukungan teknologi informasi dimana seтиa mеnијu ke era digital, baik mekanisme maupun kontennya (Elyas, 2018) .

Pemanfaatan Posbindu PTM masih rendah, karena komunikasi dan sosialisasi kepada organisasi yang ada di desa belum dilakukan. Beberapa artikel melaporkan masyarakat belum mengetahui manfaat Posbindu PTM, dan menganggap kegiatan Posbindu PTM hanya sebagai kegiatan skrining kesehatan, sehingga menuntut adanya pemeriksaan kesehatan (test gula darah, kolesterol, asam urat). Advokasi dan sosialisasi manfaat Posbindu PTM kepada semua pemangku kepentingan secara berulang perlu dilakukan untuk memperluas cakupan penduduk dan meningkatkan pemanfaatan. Keberhasilan pelaksanaan Posbindu PTM dalam mencegah dan mengendalikan faktor risiko PTM di Kota Depok dan Kota Bengkulu diperoleh karena manfaat Posbindu PTM terinternalisasi dengan baik bagi para pemangku kepentingan terkait. (Rahajeng, Oemiyati and Kusumawardani, 2006; Kusumawardani and Rahajeng, 2007; Yandrizal et al., 2018)

Pelaksanaan Posbindu PTM secara komprehensif dapat mencegah dan mengatasi masalah PTM seperti masalah hipertensi dan diabetes mellitus. Kendala dalam menyelenggarakan Posbindu PTM, utamanya karena kader belum terlatih dan belum mampu menyelenggarakan kegiatan secara mandiri. Kemanpuan untuk melakukan edukasi dan konseling faktor risiko sangat kurang. Sarana prasarana juga masih kurang memadai dalam menjangkau seluruh penduduk di setiap desa. Penyelenggaraan Posbindu PTM umumnya belum disiapkan dan direncanakan dengan baik, juga belum terbina oleh petugas kesehatan dengan baik, sehingga pelaksanaannya kurang optimal, dan tidak rutin. Sementara masyarakat sehat dan pasien PTM membutuhkannya. Efektifitas kegiatan Posbindu PTM memerlukan penguatan sistem kesehatan mulai di tingkat mikro (pasien dan keluarga), meso (Posbindu PTM, kelompok care giver), makro (Puskesmas, RS) dan tingkat mega (Pemerintah dan pemangku kepentingan). Penguatan sistem kesehatan tersebut memerlukan data dan informasi untuk perbaikan manajemen pelayanan kesehatan secara komprehensif (Kassa and Grace, 2016)

Permasalahan manajemen upaya pelayanan kesehatan primer juga terjadi di Negara Cina dan Tunisia. Intervensi berbasis masyarakat dalam pencegahan dan pengendalian faktor risiko PTM secara terintegrasi lebih efektif dan ekonomis dalam pencegahan PTM. Permasalahan yang timbul terkait manajemen sistem pelayanan kesehatan primer, yaitu keterbatasan SDM, biaya operasional, dan mekanisme rujukan yang tepat. Upaya pencegahan primer tidak dapat dibiayai asuransi kesehatan, sehingga petugas kurang mendapatkan insentif. Untuk mengatasi masalah SDM dan manajemen upaya intervensi berbasis masyarakat, memerlukan waktu dan reformasi kebijakan pembiayaan pelayanan kesehatan secara nasional (Nawel Zammit et al., 2015; Xiao, 2015)

Kegiatan Posbindu PTM cenderung dimanfaatkan oleh kelompok usia pra lansia dan lansia (35 tahun ke atas), karena pelaksanaan umumnya diintegrasikan dengan kegiatan Posyandu Lansia. Sesuai petunjuk teknis, pelaksanaan kegiatan Posindu PTM perlu diintegrasikan dengan kegiatan kelompok masyarakat di desa yang sudah aktif berjalan, seperti karang taruna, Majelis Taklim/Jemaat ibadah, dengan asaran kegiatan usia 15-59 tahun. Manfaat bagi remaja ditemukan di DI Jogyakarta dan DKI Jakarta. Kelompok remaja dapat dilatih dan berperan menjadi kader Posbindu PTM, dan dapat menjadi agen pengubah dalam upaya pencegahan faktor risiko PTM khususnya pada kelompok remaja. Keberadaan remaja sebagai kader dapat meningkatkan partisipasi remaja pada kegiatan Posbindu PTM (Yulyana et al., 2018)

Sementara peluang pelaksanaan kegiatan sebagaian besar karena dukungan pemangku kepentingan setempat yaitu Kepala Desa, Sekolah Tinggi Kesehatan setempat, dan Tokoh Masyarakat. Kerjasama dengan Sekolah Tinggi Kesehatan merupakan peluang kemitraan yang dapat menguntungkan kedua pihak. Dukungan keluarga dan dukungan tokoh masyarakat berhubungan dengan keaktifan penduduk melakukan kegiatan Posbindu PTM, dan 
partispasi anggota keluarga. Posbindu PTM yang mendapat dukungan Tokoh Masyarakat dan akademisi, umumnya dapat menyelenggarakan kegiatan secara rutin dan komprehensif. Diketahui faktor yang berhubungan dengan pemanfaatan Posbindu PTM adalah faktor predisposisi (pendidikan, pekerjaan, pengetahuan, sikap, persepsi dan peran keluarga) dan faktor pemungkin terhadap Posbindu PTM yaitu keberadaan atau kehadiran petugas kesehatan dan kader kesehatan. Kinerja kader yang tinggi dapat meningkatkan pengetahuan peserta dan menurunkan proporsi faktor risiko PTM. (Kiting, Ilmi and Arifin, 2017).

\section{Pemanfaatan kegiatan Posbindu}

PTM dipengaruhi oleh pengetahuan, kelengkapan sarana dan prasarana serta dukungan keluarga. Informasi ini menunjukkan pentingnya menyiapkan kegiatan sesuai tahap tahap penyelenggaraan kegiatan sesuai petunjuk teknis. Sebagai langkah awal, penting disosialisasikan pada target sasaran tentang PTM, beban penyakit, pengaruh faktor risiko dan manfaat Posbindu PTM dalam deteksi dan tindak lanjut dini faktor risiko PTM. (Kementerian Kesehatan R, 2015). Puskesmas diharapkan mampu menyelenggarakan pelayanan kesehatan PTM secara komprehensip mulai dari promotif, preventif, kuratif dan rehabilitatif. Pelaksanaan kegiatan Posbindu PTM di Desa Terong dan Jatimulyo di wilayah Kecamatan Dlingo Bantul telah direncanakan dan dilaksanakan secara optimal sesuai pentunjuk teknis. Kemandirian warga menjadi berkembang dengan dihasilkannya kader setempat yang telah siap untuk menjalankan kegiatan Posbindu PTM secara rutin setiap bulan. Dukungan perangkat desa sangat membantu pelaksanaan Posbindu PTM dan sangat penting bagi keberhasilan pelaksanaan Posbindu PTM. Keberhasilan desa dalam melaksanakan Posbindu PTM ini, dapat menjadi percontohan bagi desa lain dalam penguatan kegiatan Posbindu PTM (Pradana, Marfianti and Trimulyaningsih, 2018).

Implementasi kegiatan Posbindu PTM memerlukan dukungan kebijakan yang kuat, mengingat kegiatan memerlukan dukungan keterlibatan pemangku kepentingan dari banyak sektor. Penguatan dan sinkronisasi strategi disemua tingkat pemerintahan diperlukan agar kegiatan Posbindu dapat dilaksanakan secara optimal, dan tujuan penurunan prevalensi faktor risiko PTM di Indonesia dapat tercapai. Kegiatan pemeriksaan faktor risiko PTM melalui Posbindu PTM merupakan Standar Pelayanan Minimal (SPM) yang wajib dilaksanakan Pemda. Kewajiban Pemda ini merupakan peluang untuk penguatan manajemen Posbindu PTM. Adanya SK Walikota tentang pelaksanaan Posbindu PTM seperti di Kota Solok ternyata tidak cukup mendukung pelaksanaan kegiatan secara optimal. Untuk mendapatkan dukungan biaya, sarana dan prasarana dalam pelaksanaan Posbindu PTM diperlukan Perwako tentang SPM bidang kesehatan di masing-masing kabupaten/kota, yang mencakup kegiatan Posbindu PTM. Kajian kebijakan Permenkes no 71 tahun 2015 merekomendasikan perlunya payung hukum untuk operasional Posbindu PTM dan peningkatan dukungan pemangku kepentingan di kabupaten/kota. Regulasi tersebut diperlukan untuk memperkuat koordinasi dan operasionalisasi upaya pencegahan dan pengendalian faktor risiko PTM termasuk kegiatan Posbindu PTM(Christijani et al., 2018; Alfiyah and Pujiyanto, 2019) .

\section{KESIMPULAN DAN SARAN}

\section{Kesimpulan}

Pelaksanaan Posbindu PTM umumnya belum optimal, kegiatan lebih banyak dimanfaatkan untuk memantau faktor risiko hipertensi dan diabetes mellitus. Pasien PTM memanfaatkan Posbindu PTM untuk memantau faktor risikonya. Kegiatan umumnya dimanfaatkan oleh kelompok usia 35 tahun ke atas. Kegiatan belum dilaksanakan secara rutin dan belum komprehensif, karena kendala keterampilan dan kompetensi kader dalam melakukan edukasi/konseling, keterbatasan dana operasional, sarana prasarana. Sementara kelompok usia remaja berpotensi menjadi kader Posbindu PTM. Integrasi pelaksanaan kegiatan yang berpotensi efektif untuk memperluas cakupan penduduk yaitu integrasi dengan program Kesehatan Remaja, dan PIS-PK. 


\section{Saran}

Penguatan manajemen Posbindu PTM, pembinaan petugas di tingkat Puskesmas dan peningkatan kemampuan kader sangat diperlukan. Penguatan regulasi diperlukan dalam optimalisasi pelaksanaan SPM bidang kesehatan tingkat kabupaten/kota. Pelaksanaan di lingkungan tempat tinggal sebaiknya diintegrasikan dengan PIS-PK dan Program Kesehatan Remaja guna meningkatkan cakupan penduduk utamanya kelompok usia di bawah 35 tahun. Peningkatan kapasitas petugas dan kader dapat menggunakan metode pembelajaran e-learning dengan kelas virtual (e-learning), dan media informasi dan komunikasi yang berkembang di masyarakat antara lain whatsApp, youtube dan aplikasi android lainnya. Kemajuan teknologi informasi seperti Artifisial Intelegensia (kecerdasan buatan), juga perlu dimanfaatkan agar komunikasi dan trasfer pengetahuan lebih efektif dan efisien.

\section{KONTRIBUTOR PENULIS}

Kontributor utama artikel ini adalah ER, memiliki tugas untuk analisis dan sintesis data serta penulisan artikel. Sementara EN sebagai kontributor anggota yang bertugas melakukan pengumpulan data dan informasi serta ekstraksi data.

\section{UCAPAN TERIMAKASIH}

Ucapan terima kasih kami sampaikan kepada Kepala Puslitbang Upaya Kesehatan Masyarakat dan ketua PPI Puslitbang Upaya Kesehatan Masyarakat, yang telah memberikan kepercayaan dan kesempatan dalam penulisan artikel pada Jurnal ini.

\section{DAFTAR PUSTAKA}

Alfiyah, A. and Pujiyanto, P. (2019) 'an Analysis on the Implementation of the Integrated Guidance Post (Posbindu) Activities for NonCommunicable Diseases At Bogor City in 2018', Journal of Indonesian Health Policy and Administration, 4(1), pp. 11-15. doi: 10.7454/ihpa.v4i1.2388.

Ana Mardiyaningsih, Nur Ismiyati, T. (2018) 'Optimalisasi Peran Kader Posbindu dalam P4Gn dan PTM', 2(2), pp. 17-25.
Andayasari, L. and Opitasari, C. (2020) 'Implementasi Program Pos Pembinaan Terpadu Penyakit Tidak Menular di Provinsi Jawa Barat Tahun 2015', Jurnal Penelitian dan Pengembangan Pelayanan Kesehatan, 3(3), pp. 168-181. doi: 10.22435/jpppk.v3i3.2713

Christijani, R. et al. (2018) Kajian Kebijakan Permenkes No 71 Tahun 2015 Dalam Pelaksanaan Program Posbindu Ptm Faktor Risiko PTM Pada Penduduk Usia 15-55 Tahun. Jakarta.

Direktorat Jenderal Pencegahan dan Pengendalian Penyakit, D. P. dan P. P. T. M.; K. K. R. I. (2017) Buku Rencana Aksi Nasional Pencegahan dan Pengendalian Penyakit Tidak Menular.

Dwi Astuti, E., Prasetyowati, I. and Ariyanto (2016) 'Gambaran Proses Kegiatan Pos Pembinaan Terpadu Penyakit Tidak Menular di Puskesmas Sempu Kabupaten Banyuwangi', e-Jurnal Pustaka Kesehatan, 4 No1, pp. 160 167.

Elyas, A. H. (2018) 'Penggunaan Model Pembelajaran E-Learning Dalam Meningkatkan Kualitas Pembelajaran', Jurnal Warta, 56(04), pp. 111.

Grace Sicilia, Fatwa Sari Tetra Dewi, R. S. P. (2018) 'Evaluasi kualitatif program penyakit tidak menular berbasis Posbindu di wilayah kerja Puskesmas Muara Bungo I', Jurnal Kebijakan Kesehatan Indonesia : JKKI, 7(2), pp. 88-92. doi: 10.22146/JKKI.36117.

Haiti, M., Anggraini, N. and Tominik, V. I. (2020) 'Pemanfaatan Pos Pembinaan Terpadu Penyakit Tidak Menular (PTM) Pada Penderita Hipertensi', III, pp. 1-13. doi: 10.26699/jnk.v5i1.ART.p020.

Jayusman, T. A. I. and Widiyarta, A. (2018) 'Efektivitas Program Pos Pembinaan Terpadu (POSBINDU) Penyakit Tidak Menular (PTM) Di Desa Anggaswangi Kecamatan Sukodono Sidoarjo', Dinamika Governance: Jurnal Ilmu Administrasi Negara, 7(2). doi: 10.33005/jdg.v7i2.1207.

Kassa, M. and Grace, J. (2016) 'The Global Burden and Perspectives on Noncommunicable Diseases (NCDs) and the Prevention, Data Availability and Systems Approach of NCDs in Lowresource Countries', Intech, i(tourism), p. 13. doi: http://dx.doi.org/10.5772/57353.

Kemenkes (2016) 'Peraturan Menteri Kesehatan No.43 Tahun 2016 tentang Standar Pelayanan Minimal Bidang Kesehatan'.

Kemenkes RI (2018) Laporan Hasil Riset Kesehatan Dasar (Riskesdas) Indonesia tahun 2018 , Riset Kesehatan Dasar 2018.

Kementerian Kesehatan R (2015) Peraturan Menteri Kesehatan Republik Indonesia No 71 tahun 2015 Tentang Penanggulangan Penyakit Tidak Menular. Indonesia: Kementerian Kesehatan.

Kementerian Kesehatan RI (2015) 'Pemenkes No 5 Tahun 2017 tentang Rencana Aksi Penanggualangan Penyakit Tidak Menular Tahun 2015-2019', (96), pp. 1-26. 
Kementerian Kesehatan RI (2019) Laporan Tahunan Direktorat Pencegahan dan Pengendalian PTM Tahun 2019. Jakarta.

Kiting, R. P., Ilmi, B. and Arifin, S. (2017) 'Faktor Yang Berhubungan Dengan Kinerja Kader Posbindu Penyakit Tidak Menular', Jurnal Berkala Kesehatan, 1(2), p. 106. doi: 10.20527/jbk.v1i2.3149.

Kusumawardani, N. and Rahajeng, E. (2007) 'Policy Support and Community Participation to Control Life Style Risk Factors in Middle Lower Income Community in Depok Municipality Indonesia', in. Indonesia", 19th World Conference of Health Promotion and Health Education, Vancouver 10 - 15 June 2007.

Maharani, Sibagariang, E. E. and Ginting, R. (2018) 'Faktor-Faktor yang Mempengaruhi Pemanfaatan Pos Pembinaan Terpadu Penyakit Tidak Menular (Posbindu PTM) di Wilayah Kerja Puskesmas Glugur Darat Tahun 2018', Jurnal Kesehatan Masyarakat dan Lingkungan Hidup, (2).

Mashdariyah, A. and Rukanah (2019) 'Peran Masyarakat Dalam Kegiatan Posbindu PTM di Kelurahan Lumpur Kabupaten Gresik Tahun 2019', Midwiferia Jurnal Kebidanan, 5(2), pp. 1-11.

Najiyati, I. et al. (2019) 'Sekolah Kader Protector Jaten: Upaya peningkatan pengetahuan dan keterampilan kader remaja posbindu PTM di Dusun Jaten, Yogyakarta', Journal of Community Empowerment for Health, 2(1), pp. 43-52. doi: 10.22146/jcoemph.41293.

Nawel Zammit et al. (2015) 'Three Years CommunityBased Intervention Program to Prevent Noncommunicable Disease Risk Factors in Sousse, Tunisia', J. of Health Science, 3(2), pp. 95-102. doi: 10.17265/2328 7136/2015.02.006.

Notoatmodjo, S. (2012) Promosi Kesehatan \& Ilmu Perilaku, Jakarta: Rineka Cipta.

Nugraheni, W. P. and Hartono, R. K. (2018) 'Strategi Penguatan Program Posbindu Penyakit Tidak Menular Di Kota Bogor', Jurnal Ilmu Kesehatan Masyarakat, 9(3), pp. 198-206. doi: $10.26553 /$ jikm.v9i3.312.

Pradana, D. A., Marfianti, E. and Trimulyaningsih, N. (2018) 'Iptek Bagi Masyarakat (IBM) Desa Terong Dan Jatimulyo dalam Pengelolaan Hipertensi dan Diabetes Melitus', AJIEAsian Journal of Innovation and Entrepreneurship, (May), p. 2.

Primiyani, Y., Masrul, M. and Hardisman, H. (2019) 'Analisis Pelaksanaan Program Pos Pembinaan Terpadu Penyakit Tidak Menular di Kota Solok', Jurnal Kesehatan Andalas, 8(2), p. 399. doi: $10.25077 /$ jka.v8i2.1018.

Rahajeng, E. et al. (2004) An Intergrated Community Based Intervention Program on Common Risk Factors of Major Non Communicable Diseases in Depok West Java Indonesia 2003 - 2004 (Demonstrated Area Report).

Rahajeng, E. et al. (2006) Monitoring and evaluation of the integrated community-based intervention for the prevention of NCD in Depok West Java, WHO-SEARO.
Rahajeng, E. et al. (2012) Petunjuk Teknis Pos Pembinaan Terpadu Penyakit Tidak Menular (Posbindu PTM). Pertama, Ditjen Pengendalian Penyakit dan Penyehatan Lingkungan, Kementerian Kesehatan RI. Pertama. Jakarta.

Rahajeng, E. et al. (2013) Pedoman-Umum-PosPembinaan-Terpadu-Penyakit-TidakMenular. Kementerian Kesehatan RI.

Rahajeng, E., Oemiyati, R. and Kusumawardani, N. (2006) 'Efektifitas Posbindu PTM dalam Penurunan Prevalensi Faktor Risiko PTM di Kota Depok', in Simposium Nasional ke 3 Hasil Penelitian dan Pengembangan Kesehatan. Jakarta.

Sari, D. W. R. and Savitri, M. (2018) 'Faktor-Faktor yang berhubungan dengan Pemanfaatan POSBINDU Penyakit Tidak Menular (PTM) di Wilayah Kerja PUSKESMAS Kecamatan Setia Budi Kota Jakarta Selatan Tahun 2018', Jurnal Kebijakan Kesehatan Indonesia : JKKI, 7(2), pp. 49-56. doi: 10.22146/JKKI.36849.

Sasongko, H. P., Nanda, F. D. and Fitriyati, F. (2019) 'Community Knowledge Level About The Utilization Of Integrated Coaching Pos Of Noncomunicbale Disease (Posbindu PTM) With The Prevalence Of Noncommunicable Disease At Age 15 - 59 In Working Area Of Wonosobo Health Center In Srono Banyuwangi 2018', in PROCEEDING THE 4th INTERNATIONAL NURSING CONFERENCE "LIFE CYCLE APPROACH FOR SUCCESSFUL AGING" ISBN : $978-602-6988-78-2$, pp. 165 172.

Suhbah, W. D. A., Suryawati, C. and Kusumastuti, W. (2019) 'Evaluasi Pelaksanaan Program Pos Pembinaan Terpadu Penyakit Tidak Menular (Posbindu PTM) Puskesmas Sukolilo I Kabupaten Pati', Jurnal Kesehatan Masyarakat (e-Journal), 7(4), pp. 647-657.

Umayana, H. T. and Cahati, W. H. (2015) 'Dukungan keluarga dan Tokoh Masyarakat terhadap Keaktifan Penduduk ke posbindu PTM', Jurnal Kesehatan Masyarakat, 11(1), pp. 96101

Wiwi, T. W., Yanna, H. W. and Panggabean, M. S. (2018) 'Faktor Pemanfaatan Program Posbindu PTM', Kesehatan Ilmiah Indoneisa, $3(2)$.

Xiao, Y. (2015) 'Community-based integration of management of non-communicable diseases in China', Chronic Diseases and Translational Medicine. Elsevier Masson SAS on behalf of Académie des sciences, 1(3), pp. 133-140. doi: 10.1016/j.cdtm.2015.07.001

Yandrizal et al. (2018) 'Stakeholder collaboration model to empower integrated health education centers for non-communicable diseases: A study in Bengkulu', Indian Journal of Public Health Research and Development, 9(1), pp. 133-138. doi: 10.5958/0976-5506.2018.00025.6.

Yandrizal, Y. et al. (2016) 'The Empowerment of Integrated Development Post of Non- 
Communicable Diseases in Efforts to Prevent and Control Non- Communicable Diseases', International Journal of Public Health Science (IJPHS), 5(3), p. 294. doi: 10.11591/.v5i3.4799.

Yulyana, Y. et al. (2018) 'PROTECTOR JATEN (PROgram deTEksi dini dan Cegah penyakiT
Oleh Remaja Jaten) sebagai upaya peningkatan partisipasi remaja dalam Posbindu PTM di dusun Jaten, Yogyakarta', Berita Kedokteran Masyarakat, 34(11), pp. 4-9. doi: 10.22146/bkm.40592. 